\title{
A Perinatal Interpretation of Frightening Near-Death Experiences: A Dialogue with Kenneth Ring
}

\author{
Christopher M. Bache, Ph.D. \\ Youngstown State University
}

\begin{abstract}
While endorsing several of Kenneth Ring's conclusions, I propose a more comprehensive interpretation of frightening near-death experiences (NDEs). I criticize Ring's interpretation of meaningless void NDEs as emergence reactions and argue that all three forms of frightening NDEsinverted, hellish, and meaningless void experiences-are better understood as rooted in the perinatal level of consciousness. I expand Ring's account of resistance to ego death as the cause of these NDEs, and develop the broader implications of a perinatal reading of frightening NDEs. Finally, I introduce and explore parallels with the "dark night of the soul" experience.
\end{abstract}

Anyone familiar with Stanislav Grof's work cannot help but be struck by the phenomenological parallels between perinatal symptomatology (Grof, 1975, 1985, 1988) and frightening near-death experiences (NDEs) (Atwater, 1992; Grey, 1985; Greyson and Bush, 1992; Irwin and Bramwell, 1988; Rawlings, 1978). These extensive parallels suggest that Grof's concept of the perinatal level of consciousness may hold an important key to understanding these enigmatic NDEs. Kenneth Ring is aware of these parallels and discussed them in his analysis of the meaningless void variety of NDE in his article, "Solving the Riddle of Frightening Near-Death Experiences" (1994). Ring's analysis is insightful and productive, yet $I$ believe that the parallels with perinatal experience are much more extensive than he has recognized.

Christopher M. Bache, Ph.D., is Professor of Philosophy and Religious Studies at Youngstown State University. Reprint requests should be addressed to Dr. Bache at the Department of Philosophy and Religious Studies, Youngstown State University, Youngstown, $\mathrm{OH} 44555-3448$. 
The purpose of this paper, therefore, is to attempt a solution to the riddle of frightening NDEs by bringing Grof's paradigm to bear on the problem. Specifically, I argue that all three types of frightening NDEinverted, hellish and meaningless void experiences-show distinctive perinatal features, not just the meaningless void type, as Ring suggested. Accordingly, I propose that all three are best understood as rooted in the perinatal level of consciousness and that the differences between them are primarily differences of degree, not kind. This argument challenges Ring's suggestion that meaningless void NDEs are not true NDEs but emergence reactions to inadequate anesthesia. Establishing the perinatal roots of frightening NDEs also allows me to deepen Ring's analysis of resistance to ego death as their cause, to suggest new directions for future research, and to reframe our thinking about these NDEs by noting some provocative parallels to the mystic's "dark night of the soul" experience.

Let me state candidly at the outset a basic conviction that informs this approach to the problem. Put succinctly, it is this: that what we catch glimpses of in NDEs, we get sustained looks at in therapy with lysergic acid diethylamide (LSD). In NDEs we get short, intense, and usually unrepeated access to intense states of consciousness that lie outside sensory consciousness. Studying large numbers of NDEs gives us a more complete picture of this terrain, but we are always limited by the fact that our data base is a collection of (for the most part) one-timeonly forays beyond space/time consciousness.

In LSD therapy, on the other hand, we get extended and repeated access to a variety of states of consciousness that appear phenomenologically to overlap with and subsume the NDE states. In both contexts, studying the experiences of many persons stabilizes and extends our vision, but the greatest advantage of the therapeutic context is repetition. Repeated immersion in these nonordinary states activates and dramatizes the larger, organic processes involved. Processes that we see piecemeal in NDEs, therefore, are seen more comprehensively across a long string of therapeutically focused LSD sessions. If this assumption has merit, Grof's model should be able to help us solve the riddle of frightening NDEs: why do they occur and what do they represent?

\section{Common Ground With Ring}

Let me begin by identifying three central points of Ring's presentation with which I am in complete agreement, and which constitute common ground in our approaches. First, frightening NDEs are not as 
real as radiant NDEs; they do not have the same ontological status. As Ring expressed it, "it is the transcendent and not the frightening NDE that is, after all, a leaking through of ultimate reality." In Grof's approach to therapy, the perinatal matrices eventually consume themselves, yielding permanently to the transpersonal realities they had obscured.

Second, frightening NDEs can sometimes convert to pleasant NDEs. Setting aside for the moment the final disposition of meaningless void experiences, Ring's demonstration that both inverted and hellish NDEs, when yielded to, convert themselves to pleasant NDEs is important for two reasons. First, it demonstrates that these NDEs and transcendent NDEs are two aspects of an underlying, organic process. Second, it demonstrates that they represent a truncated form of the radiant near-death experience. In them a process that is triggered by nearly dying is interrupted and sometimes arrested. These frightening NDEs can thus be thought of as incomplete NDEs.

Third, Ring's suggestion that frightening NDEs are caused by our resistance to ego-death opened up an exciting new line of thinking in the discussion. A Course in Miracles (1975) is in complete agreement with Grof's observations on this point: ultimately, we suffer because we resist the fact that the personality, which we had taken as our identity, does not exist as anything real or enduring. I suggest, however, that Ring's account of this resistance did not go deep enough, as Grof's paradigm indicates that this resistance is actually rooted in the perinatal level of consciousness.

\section{The Parallels With Perinatal Experience}

Ring convincingly argued, with Grey's support (1985), that hellish NDEs are "merely more intense versions of 'inverted' NDEs." His presentation of the case of Howard Storm, in which a hellish NDE converted to a pleasant NDE, removed the only remaining obstacle from Greyson and Bush's study (1992) to viewing inverted and hellish NDEs as differing only in severity. I will therefore focus my attention on hellish and meaningless void experiences. If it can be demonstrated that these two types of NDEs share a common origin, we will be on safe ground assuming that the same holds true for inverted cases.

Ring did an excellent job of demonstrating the close parallels between meaningless void NDEs and Grof's Basic Perinatal Matrix II (BPM II) experiences. In both contexts individuals experience existence as completely devoid of purpose and doomed to failure. All our 
attempts to construct meaningful lives and to create anything beautiful are seen as utterly futile. Death and destruction are the paramount realities that despoil and mock our dreams. In both contexts persons must confront agonizing feelings of metaphysical alienation, loneliness, and desperation. Everything appears hopeless and completely without meaning.

What Ring left out of the picture, however, is the fact that the anguish of BPM II frequently culminates in profound experiences of hell. Indeed, Grof observed that the experience of hell is often the deepest level of BPM II. For example, in Realms of the Human Unconscious he wrote:

More frequently the activation of this matrix results in a rather characteristic spiritual experience of "no exit" or "hell." The subject feels encaged in a claustrophobic world and experiences incredible physical and psychological tortures. This experience is characterized by a striking darkness of the visual field and by ominous colors. Typically, this situation is absolutely unbearable and, at the same time, appears to be endless and hopeless...

The characteristic elements of this pattern can be experienced on several different levels; these levels can occur separately, simultaneously, or in an alternating fashion. The deepest levels are related to various conceptions of hell, to situations of unbearable physical, psychological, and metaphysical suffering that will never end, as they have been depicted by various religions. (1975, p. 116; my emphasis)

If we compare this summary of BPM II experiences with Grey's summary of negative and hellish NDE experiences, the parallels are striking:

A negative experience is usually characterised by a feeling of extreme fear or panic. Other elements can include emotional and mental anguish, extending to states of the utmost desperation. People report being lost and helpless and there is often an intense feeling of loneliness during this period coupled with a great sense of desolation. The environment is described as being dark and gloomy, or it can be barren and hostile....

The hell-like experience is defined as being one which includes all the elements comprehended in the negative phase, only more so in that feelings are encountered with a far greater intensity. There is often a definite sense of being dragged down by some evil force, which is sometimes identified with the powers of darkness. At this stage, visions of wrathful or demonic creatures that threaten or taunt the individual are occasionally described, while others recount being attacked by unseen beings or figures which are often faceless or hooded. The atmosphere can either be intensely cold or unbearably hot. It is 
not uncommon during this phase of the experience to hear sounds that resemble the wailing of 'souls' in torment, or alternatively to hear a fearsome noise like that of maddened wild beasts, snarling and crashing about. Occasionally, respondents will report a situation that resembles the archetypal hell in which the proverbial fire and an encounter with the devil himself are experienced. (Grey, 1985, p. 58)

To fully appreciate the degree to which hellish BPM II experiences mirror hellish NDE experiences, one must compare individual cases. This can be done by following the references listed at the beginning of this paper. To illustrate the intimate detail of the correspondences one will find there, let me insert two cases. The first account, previously unpublished, comes from an LSD therapy session of a well-educated professional and contains paradigmatic BPM II content:

I don't know how to describe the places I was in today, the searing pain and torment of thousands and thousands of beings, myself with them, tortured to their breaking point and then beyond. I did not want to believe that regions of such unspeakable horror existed. I moved through layer after layer of anguish, descending into more and more primitive levels until eventually I reached a level I can only liken to hell itself. Excruciating pain. Unspeakable horror beyond any imaginings. I was lost in a rampaging savagery that was without bounds. The world of the damned. The worst pictures of the world's religions which universally describe the tortures of this place only touch the surface. The suffering tears you apart until you've died a thousand times and can't die any more. Then you find way to die some more.

Compare this account to the following description of a hellish NDE from the Evergreen Study (Lindley, Bryan, and Conley, 1981):

I went downstairs! Downstairs was dark, people were howling, [there was] fire, they wanted a drink of water. . . .

First we went down. ... it was pitchblack. . . .

It was not a tunnel, more than a tunnel, a great big one. I was floating down....

I seen a lot of people down there, screaming, howling. . . .

I'd say about, almost a million to me. ...

They were miserable and hateful. They were asking me for water.

They didn't have any water....

[H]e was there. He had his little horns on. ...

I know him anywhere. ...

The devil himself! (p. 114)

The phenomenological parallels between these two sets of experiences are extensive and detailed. Furthermore, their dynamic patterns 
also demonstrate striking consistencies. For example, in both contexts fighting the experience simply intensifies it, while yielding to it causes it to resolve itself into a positive transpersonal experience. If allowed to run their full course, both experiences culminate in ego death followed by spiritual rebirth (Grof, 1985), as Ring noted.

In the context of LSD therapy, the experience of hell constitutes the deepest form of the crisis of meaning. What makes hell hell is not just excruciating pain but "knowing" that this pain is completely devoid of meaning. Interestingly enough, at least some NDErs appear to agree with this assessment. In two of the four cases that Greyson and Bush (1992) listed as examples of eternal void NDEs, subjects spontaneously described their experiences in terms of Hell. One even penned a poem to this effect:

I have been to Hell.

It is not as you say:

There is no fire nor brimstone,

People screaming for another day.

There is only darkness-everywhere. (p. 105)

If, therefore, BPM II combines in a coherent manner meaningless void and hellish experiences, this suggests that these two types of NDEs might not be as distinct as Ring proposed, but might in fact have common roots in the perinatal level of consciousness. Furthermore, if inverted NDEs are correctly viewed as simply milder versions of hellish NDEs, then we find in Grof's category of perinatal experience a dimension of consciousness that underlies and unites all three types of frightening NDEs. Different aspects of BPM II appear to surface in different NDEs, sometimes separately, sometimes in conjunction with other aspects. Sometimes the experience is particularly severe, sometimes milder. These are all variations seen in the context of LSD therapy.

The only remaining obstacle to this proposal is the absence of a documented case in which a meaningless void NDE converts to a radiant NDE. Such a case would strengthen the hypothesis put forward, and indeed the prolonged failure to find such a case would weaken it. As Greyson and Bush (1992) noted, the sample of void NDEs is as yet quite small, and all we can say for sure at this point is that the jury is still out on this one. On the basis of the parallels with psychedelic experience, I predict that it is only a matter of time before such a case appears, just as Ring was able to locate a case of a hellish NDE converting where Greyson and Bush had found none. 
Before developing the perinatal interpretation of frightening NDEs further, let me clarify the import of the evidence presented thus far for Ring's interpretation of meaningless void NDEs as emergence reactions to inadequate anesthesia.

\section{Meaningless Void NDEs as Emergence Reactions}

Given the existence of a perinatal matrix that includes the full range of experiences that show up in both void and hellish NDEs, it would seem advisable that we not attempt to explain their appearance through entirely different mechanisms, but look instead for a unified explanation of their origin. If this seems a wise course of action, we then have two options. Either we move to reclassify hellish experiences together with meaningless void experiences as emergence reactions, or we drop this interpretation of meaningless void experiences altogether. I recommend the latter option for two reasons.

First, Grof (1975) has argued that neither the physical nor the psychological symptoms associated with psychedelics can be interpreted as resulting from the direct pharmacological stimulation of the central nervous system. The experiences that surface in the psychedelic state are too variegated from person to person and change too much across a single individual's multiple sessions to be reasonably interpreted as mere pharmacological artifacts. Furthermore, there is a demonstrable logic to the experiences that emerge over a string of sessions that indicates a successive unfolding of deeper and deeper layers of the unconscious.

When Ring suggested therefore that we might best understand meaningless void experiences as "reflecting mainly the effects of these anesthetic and psychedelic agents on human consciousness," he misrepresented the true psychoactive effects of psychedelics at least. Grof's data clearly indicate that we must interpret the states of consciousness triggered by LSD in terms of the psyche's inherent processes, not in terms of biological responses devoid of psychological significance. As for ketamine, Grof (1980) has criticized interpreting the peculiar states of consciousness that one experiences during awakening from this anesthetic as emergence reactions. Ketamine induces a state of dissociative anesthesia quite different from the state induced by conventional anesthetics. In low doses it functions as a psychedelic, inducing an out-of-body state in which the patient detaches from physical reality and shifts to other levels of consciousness. The parallel Ring drew to LSD and ketamine "induced" experiences, therefore, actually 
argues against interpreting meaningless void NDEs as mere emergence reactions. (It is interesting to note in this context that Ring's very unpleasant experience on ketamine was cognitively consistent with the view of life offered by $A$ Course on Miracles (1975). The essence of each is that our lives as we know them on Earth are not "real" compared to another reality outside time/space. What $A$ Course in Miracles offers as a supreme illumination nevertheless inspired horror when experienced directly. Is the source of this horror ketamine or the ego's resistance?)

There is a second and definitive reason for not classifying these experiences as emergence reactions, and this is the fact that the full range of BPM II experiences, including meaningless void experiences, can surface in therapeutic contexts that are completely drug free. In The Adventure of Self-Discovery, Grof (1988) set out the principles and methods of "holotropic therapy," a very intense form of experiential psychotherapy that combines intensive breathing, evocative music, and focused bodywork. The cases presented there demonstrate that the perinatal experiences that emerge in this context are for all intents and purposes indistinguishable from those that emerge in psychedelic contexts.

One last comment: Ring was rightly struck by Greyson and Bush's (1992) observation that the majority of their meaningless void NDE cases occurred during childbirth under anesthesia. While Ring focused on the anesthesia as a possible explanation for these experiences, I would suggest that we look to childbirth itself. Grof has observed that the experience of giving birth sometimes stimulates the emergence of the perinatal level of consciousness in delivering mothers. Given the central role of biological birth in perinatal experience, it is not surprising that giving birth should sometimes cause memories of their own birth to surface in women. Other perinatal content, such as the meaningless void aspect, would then be drawn in through association to this natal aspect, following the complex logic of the perinatal matrices.

Having said all this, I do not want to suggest that anesthesia has no role whatsoever in precipitating frightening NDEs. If anesthesia plays a part here, it lies, I think, not in generating these experiences but in lowering the resistance of ego-consciousness to the unconscious, thus allowing these powerful underlying experiences to emerge. In the final analysis, neither childbirth nor inadequate anesthesia causes these unpleasant experiences in the sense of being their ultimate source, but both may contribute to their emergence in this specific context. To understand their true cause, we have to look beyond these triggers and into the deeper psyche. 


\section{Integrating Ring's and Grey's Approaches}

Taking his lead from $A$ Course in Miracles (1975), Ring argued that the source of frightening NDEs lies in our fear of losing our egoidentity:

If, upon having an NDE, you are strongly identified with your ego and sufficiently attached to it that you cling to it like a drowning man might clutch to a raft, you will naturally bring a great deal of fear into your experience,.... Such an individual's emotional state will then tend to generate images consonant with that fear, which will only cause it to strengthen. The person will therefore continue to feel deeply menaced, as he or she is indeed threatened with extinction-as a separate ego.

Grey took a somewhat different approach in Return from Death (1985), where she suggested that hell-like NDEs might be caused by the release of negative emotions that had been trapped in the psyche. She directed our attention to the negative post-mortem bardos described in The Tibetan Book of the Dead (Evans-Wentz, 1957) and suggested that these reflect "'unfinished business' that has become trapped in the psyche or soul and which continues to cause problems until recognised and overcome" (p. 191).

Both of these approaches to the problem have merit and both contribute important pieces to the discussion, but neither by itself is sufficient, I think, to solve the riddle of frightening NDEs.

The problem with Ring's approach is one of proportion. Estimates of the incidence of frightening NDEs are preliminary and tentative but range from 1 to 22 percent of NDErs (Gallup and Proctor, 1982; Garfield, 1979; Lindley, Bryan, and Conley, 1981; Ring, 1980), with the lower figure being the more commonly cited. Yet the condition of overly identifying with our egos would appear to be nearly universal. Among the millions of persons who have had NDEs, surely more than, say, 10 percent were "strongly identified" with their egos at the time of their NDE. Why, then, did only this small percentage of them experience the kind of frightening NDEs that this attachment should have generated?

At one point Ring appeared to narrow the scope of this correlation. He cited Igor Kungurtsev's (1991) observation from his research on treating alcoholism using ketamine that persons who are very controloriented often had frightening experiences on ketamine because they had trouble giving up control of their experience. Accordingly Ring suggested that "those individuals who are unable to let go, or who enter the experience with undue apprehension for whatever reason 
(great situational fear, personal rigidity, massive religious indoctrination concerning the existence of a literal hell, etc.) would be expected to undergo 'inverted' NDEs, at least to begin with." This seems like a reasonable suggestion and may very well be a factor in individual instances, particularly in weaker, inverted cases. However, I do not think the fact that some people are more afraid of losing control of their lives than others will by itself solve the problem of proportion. The discrepancy involved is still too great.

Surely it is not the exception but the norm in our culture to approach death "with undue apprehension." While personality rigidity, religious indoctrination, or situational trauma may intensify an individual's fear of death in specific cases, the fact is that our culture is pervasively and profoundly frightened by death, and people in general are terrified at the prospect of surrendering their body/mind identities. Indeed, $A$ Course in Miracles (1975) states clearly that those who hold their ego identities lightly are still the exception, not the rule, among us humans. If this is the case, then the problem of proportion is very real for Ring's hypothesis. When so many people are frightened of death and ego-dissolution, why are so few of them propelled into frightening NDEs?

Grey's suggestion that in frightening NDEs people are confronting unresolved, negative aspects of their unconscious would also seem to have merit, particularly given the correspondence with The Tibetan Book of the Dead (Evans-Wentz, 1957). By itself, however, it fails to account for the rather narrow thematic content of these experiences. That is, if individuals were simply confronting "unfinished business" from their lives, we would expect these confrontations to show a greater variety than they in fact do.

A point of clarification is needed here. Several researchers (Greyson and Bush, 1992; Rawlings, 1978) have suggested that frightening NDEs show considerable phenomenological variety compared to the more consistent content of positive NDEs, and this would appear to contradict my claim of narrow thematic content for these experiences. I do not, however, think there is a problem here. While the imagery of frightening NDEs may be somewhat variegated, the underlying themes of these experiences are relatively narrow and well defined, as all commentators have observed. These themes, outlined above, are remarkably consistent from person to person and have an almost "archetypal" quality about them. Grey mentioned this archetypal quality but failed to give any explanation for it.

Despite this problem, I think Grey's suggestion points us in the right direction, as does Ring's focus on the role of resistance to ego-death. In the context of Grof's paradigm, both observations can be viewed as correct and complementary. By tracing the roots of frightening NDEs 
to the perinatal level of consciousness, we will be able to incorporate both of their observations into a comprehensive solution to these puzzling experiences.

\section{A Perinatal Interpretation of Frightening NDEs}

The experiential parallels cited above strongly suggest that all three forms of frightening NDEs are rooted in the perinatal level of consciousness. I now want to set out a more fully developed presentation of this proposal. Let me begin by reviewing the most pertinent features of perinatal experience, as described by Grof $(1975,1985,1988)$.

\section{Narrow and Universal Thematic Content}

In contrast to the variety of themes and issues that characterize the psychodynamic level of consciousness, the content of the perinatal level is rather narrow. It focuses on those problematic experiences that are universal and endemic to the human condition. Its themes are birth, physical pain, disease, aging, and death. It collects and stores the undigested remnants of those experiences that most seriously challenge our individual physical and psychological existence.

\section{Highly Condensed}

At the perinatal level, the unconscious is organized into highly condensed systems (COEX systems) that store our experiences in thematically congruent clusters, Basic Perinatal Matrices (BPMs) I through IV. When the perinatal level is activated, one confronts not simply individual memories and fears but highly sedimented and compressed patterns of memories and fears, the distilled residue of lifelong behavior patterns. Because the energy of a COEX system is the cumulative energy of all its component parts, such encounters are exceptionally powerful and overwhelming.

\section{The Repository of the Illusion of Separate Existence}

As the intersection of the personal and transpersonal dimensions of consciousness, the perinatal level has both personal and transpersonal aspects. It is not just the fetal level of consciousness but rather an operational mode of consciousness in which the personal and transpersonal blend, sharing their organizational patterns and structures. 
Given its hybrid nature, our description of the perinatal will differ depending on whether we are looking at it from the personal or transpersonal side of the equation.

From the personal perspective, the perinatal appears to be the basement of the personal unconscious in which are stored the undigested fragments of those experiences that have most seriously threatened our physical and psychological integrity. It is the repository of the most serious challenges to our existence. Small wonder, then, that fetal experiences would figure so large here, as they derive from that period in our development when we were most vulnerable and most easily overwhelmed by our environment.

From the transpersonal perspective, however, the perinatal domain looks quite different, and here we discover interesting common ground with A Course in Miracles (1975). From the transpersonal side, the perinatal domain looks like the residual core of the insanity of atomized existence. It is the repository of our individual and collective attempts to live the lie of separateness, to pretend that we exist as autonomous beings, isolated from the surrounding tapestry of existence. As such it represents the supreme philosophical ignorance and psychospiritual disease. The perinatal level consolidates the identity of an individual and an entire species that has not yet used its selfawareness to penetrate to the roots of its existence where it would discover its connection to the whole of life.

From the personal perspective, perinatal experience takes the form of being attacked and fighting back, of killing and being killed, until eventually we are completely and utterly destroyed. As we make the transition to the transpersonal perspective, however, these same experiences are discovered to be loving attempts to rescue us from our misguided efforts to cut ourselves off from the larger flow of life itself. Merciless attack from one perspective is merciful deliverance from another. We were not being killed at all but being birthed into a reality that is larger, more fundamental, and more "real" than physical reality. Ring's discussion of Jacob's Ladder (Rubin, Lyne, and Marshall, 1991 ) is directly on target here. Indeed, this movie could be viewed as a screenplay of the perinatal dimension.

\section{Patterns in Perinatal Experience}

In BPM II-IV, the individual must face the deepest roots of existential despair, metaphysical loneliness, and profound feelings of guilt and inferiority; but the nuance and focus of the confrontation differ in each phase and follow a developmental sequence. 
In BPM II the subject typically experiences an overwhelming assault against which he or she is utterly helpless. Tortured without chance of escape, he or she is plunged into extreme metaphysical despair. Existence appears to be completely meaningless, and feelings of guilt, inferiority, and alienation have a distinctly hopeless quality to them. This is usually the first matrix that appears in therapeutic contexts.

In BPM III many of the above themes are continued but with an essential difference. Because there is now a slight possibility of escape-the cervix is dilated-a titanic struggle for survival takes place. A frequent experience related to this matrix is the encounter with purifying fire that destroys all that is disgusting or corrupt in the individual (Grof, 1980).

In BPM IV the subject eventually loses the struggle for survival and experiences complete ego-death. His or her entire world collapses with the complete loss of all meaningful reference points. After the subject has died as an ego, he or she experiences rebirth into a trans-individual mode of consciousness. All torment suddenly ceases and is followed by experiences of redemption, forgiveness, and profound love. These experiences are subsequently deepened in a mystical direction as the subject becomes absorbed into fully developed experiences of cosmic unity characteristic of BPM I (Grof, 1975).

The death-rebirth process is never fully actualized in a single session, and many sessions of repeatedly engaging the same issues are required before one has exhausted all perinatal content. The usual pattern is that a subject working at this level will eventually experience a major perinatal crisis centering on one of the phases described above. Yielding to and resolving the crisis will usually shift the person into positive transpersonal experiences for the remainder of the session, even though perinatal content may remain for future sessions. During the final stage of a session, persons may experience reentry difficulties as their consciousness shrinks back to its normal boundaries if they get stuck in unresolved psychodynamic or perinatal material (Grof, 1980). (This pattern parallels James Lindley, Sethyn Bryan, and Bob Conley's (1981) observation that negative experiences often occur at the beginning and the end of NDEs.) If the process is continued through multiple sessions, a final death-rebirth experience will eventually consume all perinatal material. In subsequent sessions the subject will move directly into transpersonal experiences.

Let me now apply these observations to frightening NDEs. One of the important insights in Ring's Heading Toward Omega was that "What occurs during an NDE has nothing inherently to do with death or with the transition into death" (1984, p. 226; Ring's emphasis). His articulation of the parallels between transcendent NDEs and the mystical 
experiences that emerge in various meditative disciplines demonstrates that nearly dying is but a trigger that catapults persons with some consistency into higher states of consciousness that can also be cultivated through various consciousness-expanding techniques.

What happens, however, if for some reason the thrust toward this higher state of awareness does not carry someone all the way to the point of transcendence? What happens if the consciousness-expanding power of their NDE is sufficient to carry them beyond their personality consciousness but insufficient to open them to the transcendental level of their being?

The indications from LSD therapy are that these persons would get caught somewhere in the labyrinth of their deep unconscious. When persons experience a transcendent NDE, they have been catapulted through this labyrinth and end up beyond it. They have not dissolved it but have pierced it to reach the larger reality it screens. If they do not get this far, however, they will be susceptible to a perinatally tainted NDE.

We might think of such a person as stuck in the tunnel that most NDErs pass through without complication. The tunnel here represents the transition from the personal level of consciousness to the transpersonal, that is, the transition through the perinatal domain. In this context it may be significant that in three of the cases that Greyson and Bush (1992) presented, the frightening phase of the NDE began while the subject was actually in the tunnel or in the transition phase.

A perinatal interpretation of frightening NDEs both confirms and expands Grey's (1985) suggestion that in these NDEs one is confronting problematic unfinished business from one's life. Grof's paradigm expands our framework for conceptualizing this encounter by identifying a level of consciousness deeper than the personal unconscious, where the dynamics of this "unfinished business" go beyond anything envisioned by conventional psychodynamic theory. At the perinatal level of consciousness, our idiosyncratic histories begin to yield to a narrow set of issues fundamental to human existence: birth, physical pain, disease, and death. The experiences that distinguish us as individuals begin to yield to experiences that unite us with other members of our species. This turn toward the collective is more than simply a turn to collective themes, however; it is also a turn to a collective mode of experience.

According to Grof's model, the perinatal dimension of consciousness is both the basement of personal consciousness and the beginning of transpersonal consciousness. It is the region of overlap between the individual and that which the individual is part of: most immediately, 
the species mind (Bache, in press; Sheldrake, 1981, 1989). When we turn deeply within, we find that our personal experience of perinatal themes begins to merge with our species' experience of these same themes. At the perinatal level, our mind opens to the species mind, and we are drawn into collective experiences of previously unimaginable proportions. Here the line between my pain and the pain of my species is systematically blurred until it disappears. As Grof observed:

A subject can experience himself as thousands of soldiers who have died on the battlefields of the whole world from the beginning of time, as the tortured victims of the Spanish Inquisition, as prisoners of concentration camps, as patients dying of terminal diseases, as aging individuals who are decrepit and senile, as mothers and children dying during delivery, or as inmates maltreated in chronic wards of insane asylums. (1975, p. 116)

When these sorts of experiences emerge in either therapeutic or near-death contexts, they will take the form of collective ordeals centered on perinatal themes. As already noted, one of the most painful experiences associated with BPM II is the experience of hell. This hell will be not the private projection of an individual's personal pain but a genuinely collective experience. We might think of it as the creation of the species as a whole, to which the individual has gained access through his or her NDE. In the psycho-plastic world one enters after dissociating from one's body, personal and collective components will be synthesized into experiences of devastating intensity. The archetypal quality of such experiences derives from the fact that one is confronting patterns of suffering that are universal to the human condition. (Parallels with the Sidpa Bardo described in The Tibetan Book of the Dead [Evans-Wentz, 1957] are striking.)

Though intense beyond description, these hellish experiences are, as Ring argued, not as ontologically real as the transcendent experiences that will eventually emerge if one completely surrenders to this suffering. Whether experienced in the context of LSD therapy or an NDE, the transition from hell takes the form of (partial or complete) egodeath. What is dying is not anything real but merely an attachment to a partial identity. In its place arises a new identity, grounded not in our bodies but in a transcendent reality that underpins all existence.

Grof's paradigm, therefore, supports Ring's assertion that frightening NDEs are driven by our resistance to ego death. It also, however, deepens it by emphasizing that this resistance is more than situational or characterological. It is in addition a resistance that is embedded in the deepest strata of the personal and the collective unconscious. It is 
our cumulative resistance to the most fundamental spiritual truth about ourselves. This resistance may surface in a milder form in inverted NDEs or in a more severe form in hellish and meaningless void NDEs. Its roots, however, reach into the very depths of our existential confusion about ourselves.

It would seem that a perinatal interpretation of frightening NDEs has only worsened the problem of proportion that I earlier criticized in Ring, and I think this is partly true. If our resistance to ego-death is rooted in the perinatal level of consciousness, and if this level is a universal structure of consciousness, it would appear to be even harder to explain why so few persons who nearly die experience frightening NDEs.

A perinatal reading of frightening NDEs does not so much solve this problem as redefine it and thereby shift where we should be looking for answers. It suggests that the reasons some people have frightening NDEs while others do not lie less in the psychodynamic particulars of the individuals involved and more in the variables inherent in their NDEs. While I think that Ring was correct that some individuals hold on to their ego-identities more fiercely than others, I suspect that the larger share of the explanation for perinatally tainted NDEs will lie in the conditions that cause some NDEs to be weaker than others.

Why do frightening NDEs occur so infrequently? I don't know. Perhaps it happens more often than we have yet identified, as some researchers think (Clark, cited in Flynn, 1986). Perhaps more people have frightening NDEs and either do not remember them or do not report them. Alternatively, it may be the case that once a strong NDE is initiated by a biological trauma, deviations from the prototypical script are simply rare. Perhaps once certain thresholds are crossed, the psychospiritual impetus generated by nearly dying is simply strong enough to carry the large majority of persons through the perinatal and into the transpersonal dimension of consciousness without complications arising. There is much we do not understand here and much work to be done. At the present time, however, the most important point to realize is that the experiences of those few whose journey to the light is interrupted or sidetracked closely parallel experiences that occur in therapeutic contexts that are better understood and better mapped. By recognizing the perinatal features of frightening NDEs, we can incorporate them into a comprehensive model of consciousness that makes sense of them and, in this way, lessens their sting.

The interpretation of frightening NDEs offered here is, of course, a speculative hypothesis requiring further verification and refinement. One avenue of research immediately suggests itself. Grof (1980) has 
outlined a set of clinical complications that can arise when perinatal material emerges in therapy but is unresolved by the end of the session. Research into the aftereffects of frightening NDEs that do not convert to radiant NDEs might explore the degree to which these aftereffects parallel the clinical derivatives of unresolved BPM II material in LSD therapy. This is a complex assessment that must take into account the pre-existing condition of the LSD patient, but these are manageable variables if handled carefully. Correspondingly, holotropic therapy might be explored as a therapeutic option for survivors of frightening NDEs. Positive results would strengthen the hypothesis put forward here.

With further research it may be necessary to consider a modification of the perinatal thesis presented here. It may turn out to be the case that inverted NDEs will be able to be satisfactorily conceptualized in terms of the psychodynamic level of consciousness, and the perinatal level may need to be invoked only for hellish and meaningless void NDEs. I am convinced of the necessity for a perinatal interpretation for the latter two types of NDEs, but am less certain about the status of inverted NDEs. This division may end up being the preferred balancing of the arguments Ring and I have put forward. A detailed phenomenological study is needed to clarify this question. We are trying to mark divisions in the spectrum of consciousness, and inverted NDEs are clearly in a gray zone. Whatever the final determination of this matter, it will not affect the overall thrust of the argument presented here, as the perinatal is the foundation of the personal unconsciousness and the repository of our deepest illusions about our true identity and our deepest fears of ego-death.

\section{The Frightening NDE as a Purification Experience}

There is an important point that I want to make in the closing pages of this paper, and I wish to address it particularly to those who have had a frightening NDE and to those who might one day counsel someone who has had one.

Survivors of frightening NDEs are doubly alienated in our culture. First they must manage the general failure of our society even today to accept the reality of their experience. Second, and more importantly, while the majority of NDErs report basking in divine light, they were taken to hell, or at least to its doorstep. How could they not take this as a devastating commentary on their life? How could they not conclude that they were deliberately singled out for harsher treatment by some 
higher intelligence? This reaction is reinforced by theological interpretations of frightening NDEs (Rawlings, 1978). If the analysis proposed here is essentially correct, however, these are all fundamentally mistaken interpretations of what has occurred.

A frightening NDE is not an alternative NDE but an incomplete NDE. It is not necessarily a reflection of the individual's moral character but represents instead an encounter with some of the deepest structures of the psyche, structures that are universally distributed among persons. Why one person is carried through these structures while another is not has more to do with the strength and intensity of the NDE itself than with the person undergoing the experience, and these are influenced by many factors, most of which probably have yet to be identified.

Perhaps one of the clearest ways to make this point is to remind ourselves that the descent into hell has happened to some rather saintly persons. It happened, for example, to St. Teresa of Avila, the famous sixteenth-century Catholic mystic. Teresa regularly entered into nonordinary states of consciousness while deep in prayer and not infrequently left her body during these episodes. While in the out-ofbody state, she had extraordinary experiences, many of which were quite unpleasant. In her autobiography (1991/1565), which was written not for publication but to allow her superiors to assess her spiritual experiences, she described in detail one particularly difficult ordeal, a descent into hell:

The entrance, I thought, resembled a very long, narrow passage, like a furnace, very low, dark and closely confined; the ground seemed to be full of water which looked like filthy, evil-smelling mud, and in it were many wicked-looking reptiles. At the end there was a hollow place scooped out of a wall, like a cupboard, and it was here that I found myself in close confinement. But the sight of all this was pleasant by comparison with what I felt there.... My feelings, I think, could not possibly be exaggerated, nor can anyone understand them. I felt a fire within my soul the nature of which I am utterly incapable of describing.

My bodily sufferings were so intolerable that, though in my life I have endured the severest sufferings of this kind ... none of them is of the smallest account by comparison with what I felt then, to say nothing of the knowledge that they would be endless and never ceasing. And even these are nothing by comparison with the agony of my soul, an oppression, a suffocation and an affliction so deeply felt, and accompanied by such hopeless and distressing misery, that I cannot too forcibly describe it. To say that it is as if the soul were continually being torn from the body is very little, for that would mean that one's life was being taken by another; whereas in this case 
it is the soul itself that is tearing itself to pieces. The fact is that I cannot find words to describe that interior fire and that despair which is greater than the most grievous tortures and pains. I could not see who was the cause of them, but I felt, I think, as if I were being both burned and dismembered; and I repeat that the interior fire and despair are the worst things of all.

In that pestilential spot, where I was quite powerless to hope for comfort, it was impossible to sit or lie, for there was no room to do so. I had been put in this place which looked like a hole in the wall, and those very walls so terrible to the sight, bore down upon me and completely stifled me. There was no light and everything was in the blackest darkness. (pp. 301-302)

NDErs who have had similar experiences might be interested to know that Teresa considered this and her many other frightening experiences in the out-of-body state to be especially beneficial and helpful to her spiritual development! She did so not because she harbored masochistic tendencies but because she had come to understand that these ordeals were a kind of purification process. Through them something negative was being lifted from her soul. By submitting to them and following them wherever they took her, she found that her experiences of mystical union deepened.

Teresa was not alone in experiencing such ordeals, nor in recognizing their purifying function. In fact, the descent into hell is simply an extreme instance of a large set of arduous experiences that are a rather common feature of the mystic's journey. In the Christian tradition, these difficult experiences are called the "dark night of the soul," and Teresa's close friend, St. John of the Cross, is perhaps their most wellknown chronicler (1959/1584). The Vissudhimagga, a Buddhist manual of meditation practice, calls them the "Higher Realizations." Collectively these experiences represent a series of particularly harsh purifications aspirants must undergo as they slowly uncover the transcendent core of their being.

In a series of papers, I have argued extensively that these dark night experiences are also manifestations of the perinatal dimension of consciousness $(1981,1985,1991)$. In the dark night, spiritual practitioners are encountering essentially the same set of experiences that surface during the perinatal phase of LSD therapy or holotropic therapy. The experiences are the same, the patterns within these experiences are the same, and the outcome of successful engagement is the same-egodeath and spiritual rebirth into a transcendental order of existence. If NDErs occasionally experience their own version of the dark night, they can take some comfort in knowing that they are keeping rather 
distinguished company. Furthermore, they should understand that in confronting these extremely dark recesses of the unconscious, they are not being punished or judged but rather purified and made ready for their final homecoming.

A larger pattern emerges. The descent into hell and similar excruciating experiences occur on the mystic's journey to God, the LSD subject's journey to Wholeness, and the NDEr's journey to the Light-a striking confirmation of Ring's earlier contention that we must separate the NDE from the context of death in order to understand it fully. Not only in its ecstatic forms but also in its problematic forms, the NDE shows itself to be a coherent part of humanity's spiritual pilgrimage to discover its true nature.

\section{References}

Atwater, P.M.H. (1992). Is there a hell? Surprising observations about the near-death experience. Journal of Near-Death Studies, 10, 149-160.

Bache, C. (1981). On the emergence of perinatal symptoms in Buddhist meditation. Journal of the Scientific Study of Religion, 20, 339-350.

Bache, C. (1985). A reappraisal of Teresa of Avila's supposed hysteria. Journal of Religion and Health, 24, 21-30.

Bache, C. (1991). Mysticism and psychedelics: The case of the dark night. Journal of Religion and Health, 30, 215-236.

Bache, C. (In press). Expanding Grof's concept of the perinatal. Journal of Near-Death Studies.

Course in Miracles, A. (1975). Tiburon, CA: Foundation for Inner Peace.

Evans-Wentz, W.Y. (1957). The Tibetan book of the dead, 3rd ed. (Dawa-Samdup, K., trans.). London, England: Oxford University Press.

Flynn, C.P. (1986). After the beyond: Human transformation and the near-death experience. Englewood Cliffs, NJ: Prentice-Hall.

Gallup, G., Jr., and Proctor, W. (1982). Adventures in immortality: A look beyond the threshold of death. New York, NY: McGraw-Hill.

Grey, M. (1985). Return from death: An exploration of the near-death experience. London, England: Arkana.

Greyson, B., and Bush, N.E. (1992). Distressing near-death experiences. Psychiatry, 55, 95-110.

Grof, S. (1975). Realms of the human unconscious. New York, NY: Dutton.

Grof, S. (1980). LSD psychotherapy. Pomona, CA: Hunter House.

Grof, S. (1985). Beyond the brain. Albany, NY: State University of New York Press.

Grof, S. (1988). The adventure of self-discovery. Albany, NY: State University of New York Press.

Irwin, H.J., and Bramwell, B.A. (1988). The devil in heaven: A near-death experience with both positive and negative facets. Journal of Near-Death Studies, 7, 38-47.

John of the Cross. (1959). Dark night of the soul. (Peers, E.A., trans.). Garden City, NY: Doubleday. (Original work published 1584)

Kungurtsev, I. (1991). "Death-rebirth" psychotherapy with ketamine. Bulletin of the Albert Hoffman Foundation, 2(4), 2-6.

Lindley, J.H., Bryan, S., and Conley, B. (1981). Near-death experiences in a Pacific Northwest American population: The Evergreen Study. Anabiosis: The Journal of Near-Death Studies, 1, 104-124. 
Rawlings, M. (1978). Beyond death's door. Nashville, TN: Thomas Nelson.

Ring, K. (1980). Life at death: A scientific investigation of the near-death experience. New York, NY: Coward, McCann and Geoghegan.

Ring, K. (1984). Heading toward omega: In search of the meaning of the near-death experience. New York, NY: Morrow.

Ring, K. (1988). Paradise is paradise: Reflections on psychedelic drugs, mystical experience, and the near-death experience. Journal of Near-Death Studies, 6, 138-148.

Ring, K. (1994). Solving the riddle of frightening near-death experiences: Some testable hypotheses and a perspective based on A course in miracles. Journal of Near-Death Studies, this issue.

Rubin, B.J. (Writer), Lyne, A. (Director), and Marshall, A. (Producer). (1991). Jacob's ladder [Film]. Van Nuys, CA: Carolco.

Sheldrake, R. (1981). A new science of life: The hypothesis of formative causation. Los Angeles: Tarcher.

Sheldrake, R. (1989). The presence of the past. New York, NY: Vintage.

Teresa of Avila. (1991). The life of Teresa of Jesus. (Peers, E.A., trans.). Garden City, NY: Doubleday. (Original work published 1565) 